\title{
El espectador pensante. El cine de Jorge Sanjünés y el grupo Ukamau
}

\author{
Carlos Alejandro Belmonte Grey (iD https://orcid.org/(0000-(0001-9676-423X \\ Université d'Évry Val-d'Essonne, Francia \\ Universidad de Guadalajara-Centro Norte, México \\ carlosbelmontegrey@hotmail.com
}

David M. J. Wood, El espectador pensante. El cine de Jorge Sanj̈̈nés y el grupo Ukamau, México, UNAM- Instituto de Investigaciones Estéticas/La Carreta Editores E.U., 2017, 187 pp.

David Wood, doctor en Estudios Culturales Latinoamericanos por el King's College (Universidad de Londres) en 2006 y profesor investigador del Instituto de Investigaciones Estéticas de la Universidad Nacional Autónoma de México (UNAM) desde el año 2010, acaba de publicar su libro El espectador pensante. El cine de Jorge Sanjinés y el grupo Ukamau. El libro es un desprendimiento y extensión de su tesis doctoral "Revolution and Pachakuti: Political and Indigenous Cinema in Bolivia and Colombia”. Desprendimiento porque mantiene la línea de investigación lanzada desde el año 2005 y extensión porque Wood actualizó su documento original con la producción del grupo y las entrevistas e intercambios de correos electrónicos con el propio Jorge Sanjinés.

El autor hace un trabajo de historia cultural del cine político y revolucionario latinoamericano a partir de la figura de unos de los realizadores más activos y comprometidos de la segunda mitad del siglo XX. Jorge Sanjinés, como va a insistir durante su argumentación Wood, se planteó la misión de crear un cine nacional y revolucionario boliviano cuyo principal espectador debía ser -antes que la burguesía nacional, el público europeo y los festivales 
internacionales- el pueblo trabajador. Sus películas "constituyen mediaciones entre grandes discursos y acontecimientos políticos, por un lado, y sus espectadores por el otro (ya sean obreros, campesinos, clase media urbana, asistentes a festivales de cine...). Frecuentemente hay en sus películas un proceso de destilar un hecho de actualidad...” (Wood, 2017: 18).

No por tener una pretensión nacionalista Sanjinés se cerró a las influencias de sus contemporáneos, sino que reconoció la propia boliviana en el cine de Jorge Ruiz, las latinoamericanas en Fernando Birri y Fernando Solanas, las europeas con el neorrealismo italiano y, finalmente, el formalismo ruso con Sergei Eisenstein y Lev Kulechov. Esta doble función, la de crear un cine popular nacional y moderno, que terminó por llevarlo a formar parte del Nuevo Cine Latinoamericano, le permite proponer a Wood (2017, p. 21) la idea de ver el cine de Sanjinés como una "bisagra que media y abre espacio entre entornos culturales, espacios geográficos, identidades étnicas, discursos políticos, debates teóricos, procesos estéticos y formatos tecnológicos”.

Wood no pierde nunca de vista estas redes internacionales a lo largo de los cinco capítulos más la introducción y el epílogo que hacen 150 páginas del texto, a las cuales se suman otras 30 de apéndice, bibliografía, agradecimientos y un prefacio escrito por una de sus fuentes principales, Alfonso Gumucio Dagron.

En el capítulo 1 "Hacia un cine nuevo: del aprendizaje chileno a la Revolución boliviana” Wood se centra en la etapa formativa en la Pontificia Universidad Católica de Chile y en el recién fundado Instituto Fílmico, sus primeros cortometrajes y su regreso a Bolivia donde realizó Un dia Paulino (1962) y Revolución (1963), obras que muestran su afán de romper con la pasividad del espectador para involucrarlo afectiva e intelectualmente. 


\section{Carlos Alejandro Belmonte Grey}

El segundo capítulo, "Propaganda, autonomía y nación: Sanjinés en el Instituto Cinematográfico Boliviano”, comienza con el golpe de Estado del general René Barrientos en 1964, su participación como director del ICB y la creación del informativo mensual Aquí Bolivia, plataforma oficial que le sirvió para difundir sus primeras dos obras ya consideradas parte integrante de su proyecto cinematográfico: Aysa (1965) y Ukamau (1966). Aquí, además de continuar su ruptura con la pasividad tanto del realizador como del espectador va a plantear las bases de su estructura con narraciones que no se centran en las luchas políticas en proceso, sino en su capacidad de filtrar visiones y nociones existentes y emergentes sobre lo indígena a través de un estilo cinematográfico percibido como moderno, dinámico y experimental (Wood, 2017: 70).

El capítulo siguiente, "Militancia y testimonio: Yawar Mallku y El Coraje del pueblo", está enfocado en el desarrollo del cine militante y pedagógico de Sanjinés, con la fundación en 1968 de la Productora Cinematográfica Ukamau Ltda y que terminaría por costarle el exilio tras el golpe de Estado de Hugo Banzer. La realización de los largometrajes Yawar Mallku (1969) y El coraje del pueblo (1971) fueron ensayos que pasaron por el dispositivo de lo testimonial para recoger "la memoria histórica minera y dirigirla hacia una conciencia política que ya no girará alrededor del nacionalismo revolucionario, sino de la revolución antiimperialista continental” (Wood, 2017: 95).

La continuidad cronológica de la obra nos lleva al capítulo "Exilio y democracia: de El Enemigo principal a Las Banderas del amanecer" para mostrarnos sus obras fuera de Bolivia y su recorrido por la región andina, su relación internacional y la refundación del Grupo Ukamau. La producción de los largometrajes El enemigo principal (1973) y ¡Fuera de aquí! 
(1977) fueron la búsqueda de un cine andino radical (el uso permanente de tomas largas para motivar la reflexión del espectador) y revolucionario ahora ya alejado del cine testimonial y su regreso a las metáforas de los procesos de lucha del pueblo latinoamericano: "Los protagonistas indígenas aparecen nuevamente como sinécdoques de una América Latina colonizada pero que también contiene las semillas de la resistencia” (Wood, 2017, p. 113).

El penúltimo apartado, "La nación fracturada, la nación alzada: de La nación clandestina a Los hijos del último jardín” es el regreso de Sanjinés a Bolivia durante la reinstalación de la democracia junto a la renovación de su planteamiento narrativo y estético, la formación de una cinematografía denunciadora del neocolonialismo y ansiosa de respetar las temporalidades andinas y occidentales. Con La nación clandestina (1989) y Los hijos del último jardín (2004) tomó distancia de su militantismo revolucionario y se centró en la identidad y las culturas propias de los pueblos latinoamericanos. Para esto introdujo la doble temporalidad -gracias al dispositivo del plano secuencia circular- de la memoria corta y la memoria larga, cuya función es activar en el presente el pasado muchas veces monumentalizado (Wood, 2017, p. 139).

Finalmente, el “Epilogo. ¿La epopeya del pueblo?” se preocupa por los trabajos realizados con la tecnología del video y el proyecto político del Movimiento al Socialismo de Evo Morales. Insurgentes (2012) es una cinta realizada a partir del recurso de procronismo que funciona como recopilatorio de personajes históricos traídos a la contemporaneidad de Morales. Esta obra, que muestra simpatía por el presidente, sigue siendo coherente con el proyecto de Sanjinés porque sigue eludiendo las complejidades y detalles inconvenientes de "la historia para forjar una narración clara y didáctica, enfocándose en crear una historia que 


\section{Carlos Alejandro Belmonte Grey}

permite que el espectador entre en una relación emotiva con la película” (Wood, 2017, p.: 159).

Esta división del libro responde a dos situaciones que van de la mano: el momento político en Bolivia y la obra de Sanjinés en consonancia a su contexto histórico. Wood sigue de cerca las etapas del proyecto del director y lo mantiene ligado a las influencias que marcaron sus películas. De esta manera, el proyecto cultural y cinematográfico de Sanjinés y el Grupo Ukamau es constantemente mencionado: crear una obra fílmica, desde la posición del mediador (tecnología y cultura), que a la vez proponga una gramática cinematográfica propia de la cultura andina y explique los porqués y cómo de la opresión del pueblo, de la invasión imperialista y neocolonizadora. Los capítulos están permeados de las dicotomías que el autor observa en el proyecto de Sanjinés: "raza (indígena/blanco-mestizo), autoconocimiento cultural (autenticidad/alienación), temporalidad (modernidad/tradición, avanzado/arcaico), género (hombre/mujer), geografía y topografía (ciudad/campo), geopolítica (nación/imperialismo) y clase social (sectores populares nacionales obreros-campesinos/burguesías y alta burguesía neocolonizadas). El punto de tensión o de análisis consiste en el atravesamiento o la filtración de estas dicotomías: el indio aculturado por la sociedad urbana, la nación invadida por y resistente al imperialismo, el burgués alienado que aprende los valores morales del mundo rural indígena” (Wood, 2017, p. 16).

Se pueden identificar dos fuentes de información principales que acompañan los análisis fílmicos realizados por Wood. En primer lugar, los ensayos teóricos y metodológicos publicados por Sanjinés y las diversas entrevistas realizadas tanto por parte de la crítica especializada como por las personales con el autor. En segundo, la decena de análisis 
realizados por el escritor del prefacio de la obra y colaborador del director, Alfonso Gumucio Dagron. El aparato bibliográfico se extiende a la prensa y crítica cinematográfica contemporánea como elemento primordial para medir la recepción de los filmes.

Es en este punto en donde se pueden encontrar algunos resquicios al libro. Sus fuentes constantemente citadas son Sanjinés y Alfonso Gumucio, parte del Grupo. Mientras que, aunque incluidas, existe un sesgo con la bibliografía más crítica al proyecto sanjinista. Su simpatía por el realizador parece queda soportada por el mismo principio de no neutralidad que el cine de Sanjinés planteaba en sus discursos pedagógicos. Es común ver los matices subrayados por Wood ante las críticas recibidas a la obra del director boliviano. El autor insistirá en mostrar la perseverancia y coherencia de un director militante revolucionario, por ejemplo: ante su negativa de difundir sus películas en DVD o internet para controlar el tipo de espectador objetivo, estrategia que al mismo tiempo ha ayudado a su encumbramiento como realizador monumental; y en su explicita toma de posición de un cine no neutral sino de un cine que toma campo y es herramienta abiertamente pedagógica para el pueblo.

De ninguna manera que el posicionamiento de Wood ante su objeto de estudio es un señalamiento que demerite su aportación. El libro es una bocanada de aire fresco a los estudios culturales, a la historia cultural, a la historia del cine y a la historia -a secas- mexicana tan asfixiada en las temáticas sacras de México: Revolución y crisis setentera. 